\title{
Ethos, enunciación, medios. Semiótica del ethos ${ }^{1}$
}

\section{Ethos, speech, media. Semiotics of ethos}

\section{Guillaume Soulez}

Universidad de Paris III

guillaume.soulez@univ-paris3.fr

\section{Resumen}

El artículo revisa críticamente las categorías con las cuales el ethos de los conductores y locutores de los medios. Define este ethos como un mecanismo de adecuación que contextualiza el discurso de los enunciadores y orienta las expectativas de los públicos. Luego, propone su estudio comprendiéndolo como un signo icónico moral, construido a partir de procesos semióticos abductivos.

Palabras clave: Conductores, presentadores de TV, medios de comunicación, ethos, enunciación, semiótica.

\section{Abstract}

The paper critically reviews the categories with which the ethos of announcers of the media is built. It defines this ethos as an adaptation mechanism, which contextualizes the discourse of the speakers and guide public expectations. Then proposes its study understanding it as a moral iconic sign, constructed from abductive semiotic processes.

Keywords: TV announcers, media, ethos, enunciation, semiotics.

\section{Introducción}

Desde sus inicios, la semiología se ha interesado en la riqueza de la tradición retórica para imaginar su transposición semiológica para el estudio de la cultura de masas (Barthes, 1970)².

1. Texto publicado por la revista belga Recherches en communications $\mathrm{N}^{\circ} 18,2002$. Traducido desde el francés por Jacqueline Fernández Cellier.

2. Sobre la evolución de Barthes con respecto a la Retórica: Soulez, 2003. 
Ahora bien, este "retorno" de la retórica aparece, en Barthes, pero también en Genett, Todorov, o en el Grupo $\mu$, etc., como un interés que apunta principalmente a las figuras (de retórica), mientras que la Retórica antigua privilegiaba al orador y a la palabra pública en el seno de un “ágora”, ágora que parece precisamente retomar la escena mediática y en particular la escena televisiva que destaca al orador (presentador, animador, periodista, hombre público, etc.). En efecto, el texto de Aristóteles, ofrece con la noción de ethos - en una primera aproximación "la imagen que el orador da de sí mismo a través de su discurso" - un punto de anclaje muy sólido para analizar a estos oradores, su palabra y sus juegos de posicionamiento. Para llenar este vacío, nuestras primeras investigaciones sobre el ethos han tratado de dar cuenta de otra presencia de la retórica en los medios entorno al rol y a la imagen del orador, pero también de cuestionar, desde esta perspectiva, las herramientas y los métodos de la semiología para analizar las producciones audiovisuales (Soulez, 1996).

Desde el punto de vista de las disciplinas, se podría decir rápidamente que la semiología era en efecto tributaria de una historia que explicaba la desaparición de la retórica oratoria en beneficio de una retórica figural. Frente a ella, sus fuentes, la lingüística y la Poética se habían conformado con lo que quedaba de la gloriosa Retórica del siglo XIX, es decir las figuras para lo esencial, o, en el mejor de los casos una Retórica "restringida” a la Elocuencia (al "bien decir”). Evidentemente, como Perelman lo había notado (Perelman, 1988 [1958]), la Retórica no había desaparecido este tiempo de las prácticas sociales, y se había perpetuado parcialmente en el seno de la educación, pero también en el seno del espacio judicial y político (por otro lado, los Estados Unidos habían continuado durante los siglos XIX y XX la transmisión de esta herencia en los Speech Departments vinculados con el estudio y la práctica del discurso público). Como lo observa Perelman y como lo demuestra la evolución en el siglo XX de los Speech Departments en "Speech \& Communication Departments", los discursos públicos mantienen hoy en día una práctica retórica viva en los medios. De aquí, en alguna medida, la "falsa sorpresa” del redescubrimiento de la Retórica por Barthes en los años 1964-70.

Para estudiar esta práctica, desearíamos proponer aquí una semiótica del ethos para articularla en las investigaciones de la semiología de la imagen y llegar así a una descripción más completa de los signos mediáticos. Nos inspiramos en un método semiótico pragmático, tal como lo propone R. Odin (1983) o F. Jost (1992), que consiste, por una parte, en determinar cual es el contexto en el cual los signos pueden tomar sentido, y por otra parte, en estudiar las operaciones semióticas en sí mismas. En este marco, proponemos estudiar las prácticas de orador, el entorno y la percepción social de estas prácticas de discurso público, incluso en su dimensión profesional, con el fin de definir el contexto del ethos a partir del cual la semiótica es posible. En segundo lugar entonces, proponemos una transformación del ethos en matriz semiótica gracias a una semiótica basada en la enunciación con el fin de permitir el estudio de la semiotización del ethos. En una tercera etapa, objeto de un próximo trabajo, se determinará cuales son las materias significativas (por ejemplo la oralidad) en las cuales se desarrolla particularmente la semiotización del ethos. 
Por el momento, no partimos de una definición más avanzada del ethos, pero tratamos de acotarlo un poco más en cada etapa. En particular, defenderemos la idea que, para considerar el ethos en su contexto mediático, es necesario dedicar una parte importante al carácter público del ethos y a la profesión del orador y que, en el plano de las operaciones semióticas, si se quiere proponer una semiótica del ethos, hay que renunciar a un paradigma indicial (como el que rige los análisis de presentación, en particular desde Eliseo Verón) y proponer un enfoque del signo del ethos a partir de una forma específica de iconicidad.

\section{El ethos en contexto: el ethos como adecuación}

La construcción de una imagen de sí en el discurso se sitúa en la frágil frontera entre la puesta en juego del "sujeto" que se expresa y las normas sociales de la palabra pública, en particular cuando se posee, como es el caso de los periodistas, una personalidad a la vez definida y sin embargo siempre vuelta a poner en juego por los acontecimientos. Por esta razón, nos parece necesario precisar en primer lugar la relación del ethos con el "sujeto", luego reflexionar sobre lo que el ethos propone como relación con las normas morales de una sociedad, ya que a través del ethos se evalúa el carácter moral del orador. Finalmente, abordaremos el tema del orador mediático como orador profesional.

\subsection{Ethos y expresión pública}

Todo acto de expresión toma lugar en un espacio social que determina las condiciones de este acto, el estatuto de aquél que expresa, el rol quejuega este acto en la situación, etc. Dentro de estos parámetros, están los relativos a la imagen que el orador da de sí mismo a través de su discurso. Así, en una conversación entre íntimos esta imagen importa poco, ya que los interlocutores se conocen de cerca; se puede incluso decir que si uno de los interlocutores aparentara como clara manifestación del deseo de construir una imagen positiva de sí mismo, sería rápidamente criticado por el otro que le recordaría la inutilidad de esta imagen ("te conozco bien, te conozco demasiado"), incluso su nocividad en una relación auténtica ("no tienes necesidad de proceder de esta manera conmigo, iquién piensas que soy?" etc.). Al contrario, en el discurso público, el ethos juega un rol determinante al no poder acceder a un conocimiento profundo del orador, ya que él participa de la confianza que el auditor puede asignarle a éste, confianza que a veces tiene más peso que el argumento mismo, en particular cuando el auditor duda entre varias opciones o cuando el asunto es confuso. Es por eso que Aristóteles explica que se podría casi decir que el discurso toma su mayor fuerza de persuasión a partir del ethos, que el ethos es el último recurso en caso de duda.

El poder persuasivo del ethos se basa así en la idea que en una situación pública lo que muestra el orador a través de su discurso (y no el discurso que él tiene de sí mismo) revela más sobre su personalidad, su carácter moral, incluso sus intenciones, que lo que él dice, para 
retomar una distinción bien conocida. Además de Goffman con sus trabajos interaccionistas en los cuales ha insistido en el rol de esta "presentación", situándose sobre todo del lado del orador (por ejemplo con la noción de "face-work"), nos parece que el antropólogo y lingüista Edward Sapir es quien mejor explicó, por parte del auditor, cómo permanentemente observamos en un interlocutor la parte que atribuimos a su personalidad, cómo "sondeamos su personalidad" en forma permanente apoyándonos en la forma en que el individuo hace uso de los "modelos" sociales disponibles, es decir observando las "variaciones" relacionadas con la voz, con la intensidad, con los grupos de palabras, que atribuiremos a su personalidad (Sapir, 1967). Como él lo señala, Sapir se inspira aquí en el psicoanálisis; sin embargo, no describe al sujeto analítico, sino el rol de un actor social tomado en una dialéctica de la diferencia y de la conformidad social. Este "acecho" y este conjunto de trazos (voz, etc.) son la base antropológica a partir de la cual se puede concebir el ethos, pero éste, no solamente sintetiza estos elementos, sino que contempla el efecto global producido por el discurso - incluyendo por ejemplo los tipos de argumentos escogidos - y les da un sentido necesariamente público.

Una observación de Goffman a propósito de la situación de auditorio en oposición a la conversación, refuerza esta idea del "acecho" en situación pública, en la medida que, los auditorios, "separados espacialmente" del orador, "tienen derecho de escrutarlo directamente, con una franqueza que sería ofensiva en una conversación”. Por esto, el rol del auditorio para Goffman es "apreciar lo que se dice y no replicarlo directamente" (Goffman, 1987 [1980]: 147). Indiferente incluso de la mirada del orador, o de la mirada imaginaria del presentador o del hombre público que se expresa, el auditor de radio o el lector de un periódico o de una novela nos parece tener la misma capacidad de escrutar una voz, una fotografía o un texto que manifestaría tal o cual personalidad, incluso aún cuando la expresión pública del escritor o del orador radiofónico o televisivo imita a veces el tono de la conversación debido a la fragmentación del auditorio en auditores más o menos relacionados.

Nos parece importante insistir en el carácter público del ethos - la idea misma de un "ethos privado" aparece por otro lado como una contradicción, ya que es lo que muestra el orador a través de su discurso - la forma en que considera la sensibilidad de su auditorio, la elección de sus argumentos, su tono de voz, etc. no es tampoco lo que el orador "deja ver" en el sentido de dejar escapar (lapsus). Se puede, desde este punto de vista, tomar alguna distancia del uso que Sapir hace del psicoanálisis. Nos damos cuenta, entre otros, ya que el lapsus tiene su lugar en la conversación íntima (puede ser retomado, explicado o tematizado), mientras que tiene un estatus mucho más delicado en el discurso público (no se retomará o no se explicará, por ejemplo sonriendo, o se propondrá un giro metalingüístico que preserva globalmente la "cara" orador, etc.). Dejar ver, pone en tela de juicio a la persona en sí misma (o al "sujeto" del psicoanálisis), de aquí lo delicado de la situación, ya que ni el "decir" ni el "mostrar" habitual afectan hasta tal punto. Si bien el lapsus, como se dice, es particularmente "revelador", por otro lado a menudo puede perjudicar o arruinar la imagen de si que el orador ofrece en situación pública. El juicio que un auditorio puede hacer sobre el "mostrar" que manifiesta el ethos 
en oposición al juicio que puede hacer sobre el "mostrar" del lapsus, lo que el orador "deja ver", sigue estando entonces bastante relacionado con la personalidad del orador en sentido estricto, es decir la parte social de su identidad, o más exactamente la forma en que tal o cual orador proyecta una identidad en la situación social considerada, ya sea que trate de someterse a reglas sociales determinadas por la situación, o de "construir" en parte esta imagen para sacar provecho de la situación (valorizarse, aprovechar esta imagen para defender un punto de vista, etc). Que exista un vínculo entre persona y personalidad, es una evidencia incluso una necesidad, pero precisamente, el ámbito social protege parcialmente a la "persona" poniendo de relieve el control que ejerce el sujeto hablando de sí mismo en situación pública, lo que demuestra bien a contrario la idea misma del lapsus, es decir de pérdida de control. Incluso se puede decir que, por este hecho, ciertos lapsus podrán no ser notados, ya que el control estará presupuestado. También, cuando un auditorio se pronuncia sobre el ethos, se pronuncia sobre lo que el orador no dice pero muestra, sin que esto signifique sin embargo que el orador pierde el control de lo que muestra, es decir de su imagen social. El ethos está al alcance del auditorio, ya sea porque es imposible o no se puede acceder a la persona del orador, ya sea porque, al contrario, no es justamente su persona que está en juego, sino su sometimiento a una regla social (un oficial que envía sus tropas a la batalla, debe no solamente decir, sino demostrar su confianza en la operación), o la incidencia que su personalidad puede tener en un intercambio social (la confianza que determina por ejemplo una elección política). El ethos, mientras esté vinculado a una persona, es un sustituto del "sujeto", el sujeto engaña a través del ethos: éste es entonces como un sustituto de sujeto, tanto en cuanto al sujeto en sí mismo como en cuanto a quien se dirige, de aquí su carácter público y la fuerza paradojal de su expresión.

\subsection{Ethos y convencionalismos morales}

Por lo tanto, el ethos es doble: expresión de un sustituto de sujeto e imagen social del orador. Este doble carácter compromete la posición del orador en relación con lo que dice - debe parecer confiable, honesto (lo que Aristóteles llama de la palabra "areté" - virtud) y dotado de cierto sentido común, de cierta sabiduría (phrónesis) y, en relación a aquellos a los cuales se dirige, debe parecer bien dispuesto frente a su auditorio (es la eunoia). Estos "atributos" del orador se expresan en términos de moralidad, de donde la noción de "ethos" o su traducción latina por "carácter moral del orador" - el carácter moral tal como lo manifiesta el discurso (y no el verdadero carácter moral del orador). La imagen del orador se crea a partir de su moralidad, y no a partir de otros trazos de personalidad. Más exactamente, para que se pueda comprender su personalidad, ésta se ve a través de un prisma moral, probablemente porque este prisma moral interviene en la relación con el auditorio (esencialmente entorno a una forma de "respeto" del auditorio: no engañarlo, considerarlo) y, en alguna medida, en la relación del orador consigo mismo (su "sinceridad"). Podríamos preguntarnos sobre el origen de este prisma moral para comprender el discurso público, notemos simplemente aquí que esta dimensión moral del 
intercambio es una constante en la reflexión sobre las condiciones sociales del intercambio, ya sea que se trate, entre otros, del carácter normativo de las máximas convencionales de Grice, del rol de la etiqueta y de la cortesía de Goffman, del intercambio propio del discurso serio de Searle, o de las normas del intercambio comunicacional de Habermas, etc.

Existen entonces dos dimensiones de esta moralidad del ethos que son muy imbricadas: una es el respeto de las reglas del intercambio, la otra es el respeto, más generalmente, de los convencionalismos morales del grupo frente al cual - o de la sociedad en cuyo seno - el orador se expresa. Estrictamente hablando, se puede decir que el ethos sólo corresponde a la primera dimensión, que es propiamente producida por el discurso en cuanto a discurso, mientras que la segunda dimensión, proviene más de la manifestación de contenidos temáticos conformes, ya que la parte discursiva de esta segunda dimensión se limita a una especie de censura (no hacer referencia a contenidos chocantes, por ejemplo) o a la puesta en práctica de un habitus social y moral. Por esto, la primera dimensión puede atravesar los siglos mucho más que la segunda, incluso si ella está por supuesto afectada por las convenciones sociales de una época o de un grupo. A la inversa, la segunda dimensión puede servir de habitáculo a la primera (mediante una extensión del sentido de ethos, le agregaremos un adjetivo a ethos, como "ethos galante" o "ethos jansenista" por ejemplo). Areté, phrónesis y eunoia tienen aparentemente un contenido moral diferente hoy en día, y llevan nombres un poco diferentes, pero la preocupación de la cual dan testimonio sigue siendo un intercambio regulado y respetuoso.

El ethos es entonces el encuentro entre la personalidad del orador y esta preocupación moral. La situación del intercambio es visto entonces por el auditorio como una situación axiológica, a partir de la cual, dadas las circunstancias, los convencionalismos sociales y el discurso del orador, el auditorio se pronuncia sobre la "moralidad" del orador. Cuando hay una "catástrofe" (circunstancia), un hombre público, un periodista, si aparece públicamente, incluso si no tiene relación con el acontecimiento, incluso si su aparición no está relacionada con el acontecimiento, está obligado (convencionalismo) en nuestra sociedad a manifestar cierta "compasión" por las víctimas. Si este rasgo moral (del ámbito de la eunoia) no aparece en su discurso, él "falla”: el orador aparece entonces como "frío", y el resto de su discurso se verá afectado.

Esta dimensión moral es central en la adaptación del orador a su auditorio, que es una de las reglas intangibles de la Retórica. El filósofo americano Allan Gibbard, mediante un enfoque muy cercano a la Retórica antigua, propone instrumentos para analizar precisamente el sentimiento moral como fruto de una adaptación al contexto social y a las circunstancias de enunciación. Para comprender como reacciona un auditorio frente al discurso de un orador y al mismo tiempo ante la actitud de este orador, se puede considerar con Gibbard que nuestros "juicios morales" consisten en juicios sobre "como sentir" (Gibbard, 1996: VII - prefacio). Es decir nuestros sentimientos serán "justos" según si se adaptan o no, según si es adecuado o no manifestarlos en tal o tal situación. La ausencia de compasión puede ser juzgada así no desde un punto de vista psicológico que nos vuelve hacia una "interioridad", sino desde el punto de vista de una norma social: es justo sentir compasión en tal circunstancia. De hecho, explica 
Gibbard, nuestros sentimientos no están totalmente construidos, movilizados en nosotros, es la situación que los muestra de cierta forma que juzgamos adecuada a las circunstancias. El auditorio se pronuncia entonces sobre esta adecuación y no sobre el sentimiento en sí mismo, como lo demuestra Camus mediante el ejemplo de Meursault que se muestra insensible ante la muerte de su madre durante su juicio. Para sus jueces, él debería haber manifestado su emoción durante el juicio. Por otro lado, el carácter moral del orador no consiste propiamente en sentimientos morales sino en una disposición general en relación a la expresión de ciertos sentimientos. Areté, phrónesis y eunoia son tres formas de presentar la adecuación del orador a una posible serie de sentimientos que pueden ser manifestados: la eunoia, por ejemplo, no es la compasión (sentimiento moral), sino que es una disposición favorable a la manifestación de la compasión en las circunstancias apropiadas. Un orador "frío" es entonces un orador que no manifestó su compasión en el momento en que se debía, cualquiera sean sus sentimientos personales o "interiores" en relación con el acontecimiento. Por el contrario, el orador adecuado suscita en el auditorio la hipótesis que él muestra el sentimiento necesario. También, un telespectador entrevistado en una emisión sobre los antiguos presentadores de televisión, evoca a propósito de Roger Gicquel: "Si él anunciaba una catástrofe, todo eso, efectivamente, él sí tomaba parte, no sólo la comunicaba”.

\subsection{La profesión de orador}

Esta expectativa de adecuación es tanto más fuerte en el orador profesional, periodista u hombre político: disculparíamos más a un cantante que hubiese venido a hablar de su disco en un programa de televisión si no demuestra compasión con ocasión de la misma catástrofe. Tomemos el caso de los periodistas: la recurrencia en la escena pública de los términos de "objetividad", de "competencia”... demuestra que la interpretación de la expresión periodística está determinada por la percepción pública del carácter profesional del orador por un auditorio no profesional, lo que supone la existencia de lugares y de un sistema de convenios. Uno de sus lugares es en particular la prensa en sí misma, que recuerda regularmente cuales son las cualidades tanto morales como profesionales del buen periodista (se ha visto por ejemplo con ocasión de la muerte de periodistas en Afganistán). Si se toma el caso de los periodistas de televisión, se observa que el correo del lector de los suplementos de televisión de los periódicos o de las publicaciones semanales de programas, incluye numerosos comentarios públicos sobre la personalidad moral de los periodistas y en particular de los presentadores, que son los periodistas más expuestos a los auditorios. El periodista es construido por los lectores como un personaje que dispone de recursos expresivos importantes (seriedad, humor, perspectiva ... ) para mostrar su punto de vista moral.Lo hemos visto con ocasión de el despido de Bruno Masure de TF1 en 1997. En algunas semanas de revuelta contra esta decisión, los lectores levantan el retrato de $\mathrm{B}$. Masure acumulando los elementos de su personalidad y relacionándolos con el hecho de hablar de la actualidad: las cartas evocan sus bromas y su connivencia, su distancia, 
su seriedad de acuerdo a las circunstancias, un verdadero "retrato moral" del periodista en su calidad de periodista. Así, en el "Tééŕrama”, el 15 de octubre de 1997: “¿De qué derecho me privan? ¡No tengo nada que reprocharme en este aspecto! Un lazo afectivo, aunque fuese unilateral, se respeta (....) La verdadera seriedad, es "estar ahí", involucrarse realmente. Bruno Masure involucraba su persona de la única manera creíble: tomando distancia, etc." El lector de prensa, consumidor de fragmentos de vida de las estrellas de la pantalla chica, de coberturas y de entrevistas de profesional, es entonces un telespectador que se interesa en las entonaciones, mímicas, juegos de palabras ("está ahí con nosotros, conmigo, totalmente presente, incluyendo por la fuerza del falso refrán”, misma carta), por que estos giros proponen una relación personalizada con la actualidad bajo el ángulo moral y desde el punto de vista del telespectador, otorgan peso a la palabra del presentador, a pesar o más bien contra, el prompter.

La expresión de un periodista pone entonces en juego a la vez su legitimidad de orador - el estatus social, la institución o la organización mediática que lo autorizan a entregar una información - y su capacidad de orador - las manifestaciones que lo hacen aparecer digno de ser periodista. Por lo tanto, el ethos se refiere más específicamente a la capacidad del orador: muestra de lo que es capaz desde el punto de vista de la adecuación moral de su discurso a las circunstancias. En esta perspectiva - que tiene poco que ver con los criterios internos explícitos de la profesión, con la deontología - se pensaría que un periodista que no manifiesta emoción con ocasión de la muerte de una princesa muy querida (como Diana) considera poco lo que opina su público. Es un reproche que se le hizo a Bernard Langlois, presentador del $20 \mathrm{H}$ del Canal 2, al punto de conducirlo a su despido cuando comparó en 1982 la importancia de la muerte de Grace de Mónaco con la, simultánea, de Béchir Gémayel, en detrimento de la primera ya que tenía menos consecuencias políticas. Esta capacidad es evaluada con criterios muy variables según las culturas, ya que se sabe que un presentador alemán - cuya legitimidad es la de un speaker y no de un periodista - debe por el contrario atenerse a una compostura de buen gusto. El presentador francés cuya "buena" posición es marcar cierta implicancia, en particular desde la instauración del presentador único, es decir desde el periodista Joseph Pasteur en 1971 (cuyo modelo reivindicado en la época era Walter Cronkite, el "nice guy", traducido en francés por "chic type" por Pierre Desgraupes) hasta Poivre d'Arvor. Citemos un artículo de Télé 7 Jours a favor de la solución del "presentador único" a la americana en agosto de 1971: "De lunes a viernes, veinte millones de espectadores van a escucharlo, y mirarlo todas las tardes. Las autoridades no parecen temer más que un periodista de la TV acceda a la celebridad nacional. En resumen, ¿Pasteur es al igual que Walter Cronkite, un "nice guy" ? Colocando frente a frente sobre una página doble, una fotografía de Joseph Pasteur y un tapa de Life que muestre a Cronkite con la misma sonrisa discreta, el periódico evoca el arte de Cronkite que beneficia ya de un "teleprompter" pero es capaz de improvisar brillantemente cuando las circunstancias las obligan a ello", y de dar este "pequeño toque personal incapaz de ser imitado". De la misma manera, nota Télé 7 Jours, Desgraupes desea asi "pasteurizar" el noticiario.

Esta capacidad combina entonces dos aspectos interdependientes que definen ahí 
incluso, en tanto es esta interdependencia misma, el ethos: el resultado de la expresión y el posicionamiento moral. Un modo de hablar calmado y "seguro" produce la imagen de un orador sereno, una palabra "justa" es a la vez una expresión bien lograda y una posición moral, etc. De aquí los numerosos manuales de escritura para periodistas que recurren a la tradición retórica más o menos explícitamente, o en audiovisual, la formación propuesta por el Centro de Formación de Periodistas (CFJ) para la palabra en público, frente a una cámara, formación que reciben todos los aprendices de periodistas que desean trabajar en audiovisual, y que asegura como mínimo la calidad del resultado para evitar la consecuencias nefastas de una presentación mal manejada, pero evoca también la imagen que debe dar el periodista de sí mismo cuando está presente en la imagen y la forma en que puede o debe dirigirse al público. Legitimidad profesional y convencionalismos sociales o culturales, contexto político (la notoriedad del presentador único ya no amenaza a las "autoridades") al cual se podría agregar precisamente en ciertos casos la identidad social propia de tal o cual orador que goza de cierta notoriedad, constituyen entonces el fondo sobre el cual se desarrolla la capacidad del orador tal como es percibida a través de su expresión pública por un auditorio, según una interpretación moral de su actividad profesional. Pasteur es un "nice guy" porque es un periodista flemático y honesto (esto remite al contexto profesional, cultural, personal) es también, algunos años después del 68, un "nice guy" en relación con las autoridades (es el contexto político) ... Se puede fácilmente delinear lo que sería un ethos específicamente profesional a partir de estos ejecutivos tal como aparecen en la prensa o en las emisiones de radio, o de televisión dedicadas a los medios, para profesiones como las de periodistas o animadores. A la credibilidad de los periodistas (basada esencialmente en la "confianza" que produce su areté) se podría oponer la amabilidad en sentido literal de los animadores, la eunoia que aparece como la capacidad primera del animador, esta "entrega" en favor del público que puede llevar al animador a perder la mesura (phrónesis). Citemos este comentario extraído de un Télé 7 Jours de septiembre de 1971 a propósito de una nueva locutora, Jacqueline Alexandre: "su sonrisa tan natural, apenas esbozada, durante todas sus exposiciones, pronunciadas claramente, con voz alta y clara, voz conmovedora, que solicita tan gentilmente y tan discretamente un "perdón" cuando comete un raro error $(\ldots .$.$) Si su personalidad tiene relación con su apariencia, ella es el fénix de las$ locutoras".

Del mismo modo, lejos de disculpar a los oradores de hacer la demostración de su capacidad, la legitimidad de estos oradores los hace al contrario oradores profesionales que son observados más atentamente y juzgados a veces más severamente que sus invitados que sólo son oradores "amateurs" cuya capacidad no es objeto de tal interés y de tal tratamiento social. Se espera que un orador profesional recientemente llegado al escenario público, confirme su legitimidad mediante la demostración de su capacidad, como se acaba de ver (para un desarrollo de esta interacción entre legitimidad y crédito del orador periodista: Soulez 2002). A diferencia del universo aristotélico, considerar el contexto socioprofesional parece entonces ser un elemento indispensable si se va a estudiar actualmente el ethos, en todo caso en los 
medios, en la medida en que el estatus del orador (periodista, hombre político, experto....) y el rol reconocido socialmente a su palabra, su gestualidad, etc. determinan fuertemente el ejercicio de su expresión pública, es decir el marco dentro del cual el ethos toma sentido en tal o cual situación.

Si resumimos lo que este estudio del contexto general nos enseña, podríamos decir que en oposición a la imagen producida por un orador a pesar de él, el ethos puede entonces definirse más precisamente como la imagen de sí del orador en cuanto es el encuentro entre un sustituto de sujeto y una imagen social, encuentro considerado por su auditorio como una adecuación del orador a la moralidad requerida por una situación dada. Esta adecuación se mide por la capacidad del orador, es decir su facultad de producir en una situación dada un resultado expresivo que confirme un posicionamiento moral ("tomar parte"). Esta capacidad es mucho más esperada cuando el orador es un profesional de la expresión pública, lo que insiste en la importancia en el campo social, incluyendo en su manifestación mediática, del rol y del peso de los juicios en la personalidad de los oradores.

Ahora veremos como este sustrato social y cultural da lugar a operaciones semióticas tal como que un lector-telespectador puede escribir - él quien precisamente sólo tiene acceso a una "apariencia" a través de una voz clara o "emotiva" - que esta apariencia pone en juego la personalidad del o de la profesional.

\section{Semiotización del ethos}

A partir de este contexto hecho de convencionalismos sociales (en sentido amplio, incluyendo convencionalismos culturales y políticos) y reglas del intercambio que determinan las garantías que los oradores deben dar públicamente (ser un "nice guy", por ejemplo, es dar garantías de neutralidad a las autoridades, de seriedad a los telespectadores, etc.), es posible proponer una perspectiva semiótica sobre el ethos para ver como estas garantías son comprendidas mediante signos (Soulez, 2001). Es decir, pasamos de una perspectiva centrada en el punto de vista del orador (dar garantías para asegurar su ethos) a un estudio del ethos desde el auditorio (interpretar signos como pertenecientes al ethos de un orador). Si se parte de la idea que el punto de convergencia de los signos, el horizonte de la semiosis es este sustituto de sujeto que está en juego, entonces hay que recurrir a una semiótica de la enunciación. Luego, defenderemos la idea que puesto que las manifestaciones del ethos no constan de muchos indicios que conduzcan a una personalidad, esta semiótica de la enunciación no es indicial, como ciertos trabajos tienden a proponer, sino que está relacionada con otro proceso interpretativo mucho más vinculado a los estereotipos sociales. Entonces propondremos una posible explicación del acercamiento erróneo entre ethos e indicio, profundizando el análisis del cálculo inferencial al cual da lugar el ethos. 


\subsection{Ethos y enunciación: lo que el locutor L muestra del locutor $\lambda$}

En una feliz fórmula, François Jost habla de un "uso enunciativo de los signos", es decir que utilizamos los signos para construir la enunciación que se nos dirige, es decir la figura del enunciador. Incluso si él busca ante todo ilustrar su teoría polifónica de la enunciación, e incluso si no reduce la enunciación a la búsqueda de un enunciador, es interesante analizar lo que Ducrot dice del ethos desde este punto de vista.

Se sabe que Ducrot distingue el locutor del enunciador, siendo el primero el autor del discurso y el segundo el agente del acto elocutivo como en el ejemplo de una carta tipo "yo el abajo firmante..." mediante la cual es la firma quien hace de locutor - ser de discurso - un enunciador responsable de sus actos. Luego al interior del locutor, él distingue nuevamente el locutor $\mathrm{L}$ del locutor $\lambda$, el primero es el locutor como tal, es decir como ser puro de discurso (sujeto hablante), mientras que el locutor $\lambda$ es el locutor como "ser del mundo" (u objeto de la enunciación), es decir una especie de figura discursiva de un ser del mundo (Ducrot, 1984).

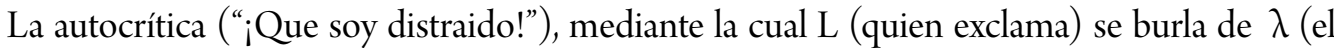
"yo" distraido) es un ejemplo de esta distinción. Para Ducrot, quien en particular, utiliza como argumento la diferencia entre "carácter moral real" y "carácter moral del orador", el ethos es atribuido a $\mathrm{L}$ ya que es un producto del discurso y no refleja a la persona real. Ahora bien, se pueda razonar de otra forma sobre el ethos. Si un periodista muestra compasión con ocasión de la muerte de una princesa (mediante una mirada apagada, voz temblorosa, algunas palabras escogidas: "acabamos de saber una noticia conmovedora, etc."), es que el locutor L muestra justamente que el ser del mundo, que también es $(\lambda)$, está afectado. Es un sentimiento que no puede corresponder a un sentimiento "real" ya que, incluso si bien $\lambda$ es un ser del mundo, sigue siendo un ser de discurso, razón por la cual no podemos acceder a su carácter moral real. La única diferencia, en cambio, entre la autocrítica y el ethos, es que $L$ dice lo que es $\lambda$ en la autocrítica ("yo" está distraido), mientras que él lo muestra en el ethos ("yo" está afectado). Consideremos entonces el ethos como lo que L muestra de $\lambda^{3}$.

Un auditor, el telespectador que hace un uso enunciativo de los signos podrá entonces tomar los signos de la aflicción - mirada apagada, etc. - como si fuese la manifestación de un locutor $\mathrm{L}$ de la pena que siente como ser del mundo. El auditor hace entonces la relación entre dos figuras discursivas ( $\mathrm{L}$ y $\lambda$ ) para atribuir a una las manifestaciones de la otra. Si el auditor considera que en la frase "acabamos de conocer una noticia conmovedora" el "nosotros" se refiere al grupo de profesionales, él establecerá un vínculo más amplio entre la manifestación de aflicción y los locutores involucrados. Así, si en la siguiente secuencia, la escena televisiva pasa de un programa a una emisión en directo que nos pone en relación con un corresponsal en Londres, esperaremos que este corresponsal también tenga lágrimas en los ojos - lo que

3. Y no como lo que L "dice" de $\lambda$, como lo había escrito demasiado rápidamente en una primera etapa de esta reflexión a partir de Ducrot (Soulez, 2001). 
fue el caso en la transmisión de France 2 cuando murió Diana (31 de agosto de 1997), con Etienne Leehnart como corresponsal del canal en Londres. En cambio, nos sorprenderemos menos con la ausencia de manifestación de aflicción del reportero en un reportaje del mismo noticiario sobre un movimiento social sin relación con la situación axiológica que constituye la muerte de Diana, es decir que no supone la misma adecuación a las circunstancias. Así, incluso si está claro que el reportero forma parte del mismo grupo de profesionales, la inferencia etótica no tiene la misma pertinencia. La situación axiológica es entonces en realidad la articulación de un contexto (es la forma social instituida que constituye por ejemplo un noticiario televisado, con sus actores legítimos, su organización, su temporalidad, su rol en la vida pública, etc.) con una circunstancia que requiere de una toma de posición moral adecuada (un acontecimiento, incluso si este acontecimiento está parcialmente construido por los medios) debido a convencionalismos sociales y profesionales. Al mismo tiempo que implica una exigencia - por parte de los actores - ella origina una semiotización por parte de los lectores, de los auditores ... delimitando la pertinencia de estas acciones y de esta semiotización.

A menudo debemos al ethos estas atmósferas emocionales en los programas de televisión, tanto sin duda porque los oradores se controlan unos a otros, como por la multiplicación de inferencias que hacemos como auditores observando los más mínimos signos que nos conduzcan a los ethos de los periodistas, para a la vez coordinarnos con su aflicción pero también para obtener información sobre la gravedad de la situación a través del ethos. Desde entonces que el "nosotros" engloba también a los auditores, el ethos es más aún el punto de anclaje de una manifestación a través de la cual el periodista reacciona "para nosotros" (es el "hombre ancla" para retomar la expresión americana "anchorman"), como se ve también en ciertas ceremonias televisadas. Ahora bien, estos signos referentes a los ethos de los periodistas ¿de qué naturaleza son?

\subsection{El ethos como ícono moral}

¿Son los indicios de una personalidad? Habría que considerar entonces que la interpretación de signos etóticos corresponde a una semiótica indicial en el sentido peirciano. Es decir que el signo sería la marca de una contigüidad, de un "contacto", de una huella enunciativa dejada por el orador en el tejido significante, como la huella dejada por la pata de un animal sobre la nieve. Incluso si no evoca el ethos, y evoca poco la palabra como lugar posible de semiotización, es la tésis de Eliseo Veron, como se sabe, en cuanto al rol del cuerpo del presentadory particularmente de la mirada de la cámara que produciría un contacto entre espectador y periodista (Veron, 1997 [1983]). Es incluso este cuerpo, esta mirada, debido a que estaríamos en contacto con ellos, y "en directo", que producirían la "confianza" que conduce a una experiencia primordial relacionada con el cuerpo y con el contacto corporal. Trataré de mostrar al contrario que el ethos no corresponde a mi entender a la indicialidad sino a una forma de iconicidad, es decir a una inferencia que se refiere al objeto en virtud de caracteres propios (similaridad) y 
no en virtud de una causalidad psíquica (indicio) o en virtud de una ley (símbolo) (Peirce, Collected Papers, cité par Eco, 1988 [1984] 201). Sin embargo, como lo recuerda Eco, lo que llamamos "signo" es a menudo el resultado de varios procesos semióticos. Y, en este sentido, como lo veremos más adelante, el ethos implica otro aspecto, depende parcialmente de otro proceso semiótico, que puede hacer pensar en el proceso que utilizamos habitualmente para decodificar un indicio.

Incluso si hablamos de "convencionalismos morales" en los cuales se basa el ethos, podemos considerar que el proceso de interpretación relacionado con el ethos no corresponde a una construcción que para aparecer hace referencia a un convencionalismo, a la utilización de una regla simbólica en el sentido peirciano. En efecto, el ethos no ejemplifica una ley, sino que se refiere a un "esquema preexistente", como lo dice claramente Ruth Amossy: "le corresponde al receptor formarse una impresión del orador vinculándolo [se podría decir comparándolo] a una categoría conocida" (Amossy, 1999: 136). Entonces hay que comprender "convencionalismo" más como un repertorio de esquemas, de "estereotipos" como dice R. Amossy. Tratando la actitud propia del orador, el receptor compara esta actitud con otras actitudes parecidas en la misma situación. Es precisamente el sentido del juicio normativo ordinario: supone una regla de ajuste, pero su funcionamiento es analógico: no me conformo con la regla, como cuando respeto la luz roja, sino con los sentimientos idénticos en una situación comparable. Imito un sentimiento, no me conformo con una regla. Entonces hay que distinguir el principio social (la regla de ajuste, el "convencionalismo" propiamente dicho que está presente en la cultura) de su realización (el ethos) ya que la realización es objeto del proceso semiótico (en este sentido, también, es decir desde el punto de vista de este proceso semiótico, la norma no es la ley). En el "estereotipo", la relación con el tipo es precisamente como la relación de la imagen con el molde. Esta relación del ethos con los esquemas morales, con los estereotipos, explica por qué, en efecto, se puede leer ahí la ideología de una época o de una sociedad, como lo observaba Barthes a propósito de la Retórica en general. En otro pasaje de este texto, él evoca la eunoia como el hecho de parecer "simpático": es decir que produce él mismo una comparación entre formas pertenecientes al mismo tipo, llenando la eunoia de un esquema contemporáneo. Si hablamos de "imagen" del orador, probablemente esto conduce al menos tanto a este proceso relacionado con la iconicidad como a alguna cosa que preexistiría, ya que se considera al ethos como la proyección de una "imagen" al momento de su aparición y no como que constituye un capital icónico. Por lo tanto, podemos definir en términos peircianos el ethos como un ícono moral.

\subsection{El ethos como construcción abductiva}

Vemos entonces que el proceso que permite identificar un ethos no es volver a la causa a partir de una traza que caracteriza al indicio. Es por esto que el "mostrar" del ethos se distingue como lo hemos visto del "dejar ver" del lapsus. Como lo recalcó Ginzburg (1980), el lapsus tiene, en 
efecto, un carácter indicial, es una traza, un síntoma, que la semiótica psicoanalítica asume para volver a la causa traumática. Hablar de indicio a propósito de la mirada de la cámara, como si las miradas se reencontraran verdaderamente, y a través de ellas los cuerpos, es finalmente tener la ilusión del intercambio de miradas para este intercambio en sí. El ethos, al contrario, es un acercamiento, lo que es el movimiento inverso de la lectura en términos de indicio: para interpretar tal gesto, tal palabra, los acerco a un modelo de gesto, a un modelo de palabra presentes en la cultura, de aquí la necesidad de mantener que el ethos no escape del enunciador, ya que nos inclinaríamos del lado de la traza de una interioridad. La interpretación etótica trabaja en superficie, al contrario, incluso comparando ethos presentes en una misma secuencia. Así, con ocasión de la cobertura en directo de la televisión rumana de la pseudo revolución de 1989, Jacques Merlino teme que un corte de transmisión signifique que el edificio de televisión alrededor del cual se desarrollan los combates sea tomado por las fuerzas fieles a Ceausescu. A lo que Daniel Bilalian, presentador central responsable, responde, mirando a la cámara, que hay que ser prudentes, ya que la situación es lo suficientemente confusa y dramática "para que agreguemos de nuestra parte". Comparando a los dos mediadores, D. Bilalian adopta el modelo del hombre de "sangre fría" (calmado, ponderado, prudente - Phronesis), en oposición a J. Merlino (relajado, imprudente ....).

Sin embargo, el proceso inferencial parece incluir un carácter precario en el ethos: existe, tratándose particularmente del ethos de los profesionales de los medios, una forma de tensión muy grande entre el sustrato esquemático (o "pre-discursivo") y la incertidumbre de la proyección circunstancial. Desde este punto de vista, como a menudo en la interpretación en términos de indicio, el proceso inferencial es abductivo. Peirce, como sabemos, distingue tres procesos inferenciales: deducción, inducción y abducción, es decir tres formar de relacionar un resultado, un caso y una regla. La hipótesis que, a partir del resultado observado, presupone la existencia de una regla que explica el caso es un ejemplo de abducción. El objetivo de la abducción es el caso, no la regla, al contrario de la inducción que apunta a la regla y de la deducción que se utiliza para estudiar el resultado como el caso de una regla. Pero, sin entrar en detalles, Eco (1994 [1990]:248 et s.) considera que existen de hecho cuatro tipos de abducción y enfrenta en particular la abducción hipercodificada (o hipótesis) que consiste en utilizar una regla conocida dada automáticamente con la ocurrencia y la abducción hipocodificada en la cual la regla retenida es la más plausible pero sigue sujeta a verificación posterior ${ }^{4}$. El ethos depende de una abducción hipocodificada: trato el resultado (el temblor de una voz) como el caso de una regla plausible: el orador adopta al parecer en esta circunstancia el temblor de la voz como la actitud habitual (regla) - por ejemplo como hacen habitualmente los periodistas

4. Las dos otras abducciones son la abducción creativa (que consiste en inventar una ley, como en los descubrimientos científicos) y la meta-abducción que consiste en decidir si el universo posible determinado por nuestras abducciones de primer nivel es idéntico al universo de nuestra experiencia, como en el caso de la investigación policial. 
- en una situación comparable (caso). Yo descarto entonces la idea que este temblor es algo que se le escapa (la regla probable descarta el lapsus) o la idea que este resultado no se puede reducir a un caso. Tratamos la mayor parte de los indicios a través de este tipo de abducción hipocodificada (sólo las huellas stricto sensu son hipercodificadas en la medida que la regla aparece casi al mismo tiempo que la huella), pero toda abducción hipocodificada no hace de un signo un indicio, como los fenómenos que se observan en astronomía por ejemplo para retomar un ejemplo de Eco (cuando dudamos entre varias leyes en astronomía para explicar un fenómeno, no se puede decir que el movimiento de un planeta es el indicio de una ley). Incluso, el ethos tampoco es inductivo en la medida que se trata de verificar que la manifestación del orador respeta una regla (así como tampoco existen "ethos privado", "ethos-infracción"), sino de observar el parecido del caso con otros casos, según una regla que no ha sido puesta en juego sino supuesta. Precisamente, el ethos siendo en realidad el producto de varios procesos semióticos, a partir de múltiples resultados, incluso múltiples casos, reunidos entorno a una figura discursiva con la cual se relacionan, y en la medida que se apunta a un sustituto de sujeto, es la multiplicación de inferencias etóticas las que construyen progresivamente, tomando de diferentes esquemas, el retrato del orador. Encontramos aquí un principio muy profundo en el funcionamiento retórico, que es pensar según una lógica de lo verosímil (eikos) en el fundamento para Aristóteles de la especificidad de la Retórica en oposición a la Dialéctica.

El signo etótico es entonces la articulación de al menos dos procesos semióticos tomados de una dinámica semiótica enunciativa: una simple proyección que trata el objeto como similar a otros, como parecido a esquemas morales presentes en la cultura (ícono moral) y un razonamiento (o un cálculo) que procede por abducción hipocodificacda y que se apoya en particular en el hecho que los medios utilizan este tipo de esquemas de interpretación a propósito de profesionales de los medios (pero también, cada vez más, a través de la prensa people, en lo que respecta a toda persona pública), de aquí un alto grado de probabilidad de encontrar estos esquemas encarnados por profesionales en acto (en artículos, radio, televisión o cine). El en-acto de la enunciación corresponde, para el auditor que lo observa, a la puesta en marcha, en el vínculo que establece entre $\mathrm{L} y \lambda$, de este doble proceso semiótico: esta relación es la que sirve de soporte en alguna medida a la proyección icónica y al cálculo abductivo. Desde el punto de vista del telespectador, Bilalian en su calidad de fuente de la enunciación muestra que Bilalian como objeto de la enunciación - "ser del mundo" - parece ser un "periodista ponderado" ya que el telespectador identifica los resultados (tono calmado, argumento de

5. Incluso si él parte del trabajo de Zadig en la obra de Voltaire a partir de indicios (polvo, marcas de herraduras en un camino), quien busca determinar a que se parece el caballo que se le acusa de haber robado, Eco nota que el proceso de abducción hipocodificada logra construir progresivamente la imagen del caballo: a medida del razonamiento de Zadig, "una imagen general coherente se dibuja", y esta imagen se realiza a partir de la idea que esta historia es "normal". No es un bromista que pasaba su tiempo a limpiar pezuñas, etc. Donde se encuentran dos trazos semióticos del ethos: la normalidad (que permite la similaridad) y la producción progresiva de una "imagen". 
prudencia, etc.) con el caso del ícono moral del hombre ponderado, categoría constituida que puede encontrar disponible en la cultura. Esta comparación es objeto entonces de un cálculo destinado a probar la verosimilitud de esta explicación. El telespectador puede, por una parte, inmediatamente comparar este ícono con la actitud adoptada en sentido contrario por el otro locutor (el ícono identificado es incluso una respuesta a esta actitud). En segundo lugar, la proyección icónica es mucho más fácil cuando L incluyó a $\lambda$ en un "nosotros" que establece un vínculo entre los dos locutores (por lo menos). Pero este "nosotros" lleva también a la profesión del periodista ${ }^{6}$; también, la explicación puede afinarse ya que este ícono es más precisamente el del "periodista ponderado", tal como la cultura lo utiliza a través de los mismos medios, como lo muestra, entre otros el caso de Joseph Pasteur.

Se podría decir para concluir esta parte, que el ethos está por lo tanto basado en una cierta tensión enunciativa ya que de una distancia entre $\mathrm{L}$ y $\lambda$ puede nacer un espacio proyectivo. El ethos produce entonces una especie de pliegue enunciativo en el desarrollo discursivo, pero este pliegue es como inmediatamente borrado una vez que el ethos es vinculado a tal o cual categoría ya conocida. Basado en un sustituto de sujeto en un teatro de sombras discursivas, el ethos juega como una falsa revelación de sujeto. Sin embargo, este pliegue permite la puesta en marcha de un doble proceso semiótico, debido a que el signo etótico es de naturaleza icónico, pero su cálculo depende de una forma particular y a menudo precaria de abducción. En el marco de una escena mediática muy a menudo efímera, en particular si se la compara con el lento trabajo de ethos de un escritor a través de un libro, es a menudo la repetición intensiva de este cálculo y no la acumulación de indicios que garantiza la estabilidad del ethos.

\section{Ethos, cultura mediática y estrategias: mezclas y aclaraciones}

Como resultado de este estudio, parece que podemos extraer algunas lecciones para el estudio del ethos en los medios. Primeramente, podríamos decir que lo esencial del ethos no está "en" los textos mediáticos estudiados, sino al contrario es transmitido por los medios en cuanto universo: es decir que todo en lo que se basa el ethos está disponible en el contexto social y cultural y no en el texto mediático que se estudia. A diferencia de un proyecto literario, artístico o filosófico que utiliza el ethos para construir una singularidad a través de uno o varios textos, que definen en espejo la obra y el escrito a través del ethos (Maingueneau, 1996), el ethos mediático no da lugar a un proceso de creación, sino que pretende la conformidad a las

6. La expresión impersonal "sin que agreguemos de nuestra parte" nos vuelve hacia un locutor-fuente que dice esto, pero el enunciador es más ambiguo (¿se refiere a una toma de posición que compromete a Bilalian o del enunciado de una regla deontológica retomada por Bilalian como simple locutor ?), incluso si los alocutorios (Merlino, pero también los telespectadores por la mirada de cámara y generalmente por la situación de audición televisiva) y los enunciadores son relativamente claros (los periodistas y los telespectadores frente a los cuales se comprometen). 
normas comunes. En cambio, los medios como sector de la vida social y cultural son uno de los vehículos principales, si no el vehículo principal, de estas normas etóticas (con diarios o emisiones dedicadas a asuntos morales o a personalidades mediáticas, tales como revistas de televisión, la prensa people y los talk-shows).

En segundo lugar, el ethos del orador mediático está limitado por las estrategias editoriales de las organizaciones mediáticas, como se ha visto con Joseph Pasteur, a menos que no sea precisamente el vector de esta estrategia como lo mostrarían en forma diferente el rol de Poivre d'Arvor durante la Guerra del Golfo en beneficio de TF1, o el del de Béatrice Schönberg o Patrice Bourret cuando murió el canal "La Cinq".

Finalmente, lo señalamos al inicio, queda por estudiar las materias y los dispositivos mediáticos en su calidad de soportes a partir de los cuales tiene lugar la semiotización. Para dar una idea, se puede decir que la imitación gráfica de una expresividad corporal en lo escrito (puntos de exclamación de suspensión, juegos con los tamaños de los caracteres, etc.) para imitar la respiración, los suspiros, etc. y todo lo que va contra lo arbitrario del signo - lo que Genette llama mimología - es un lugar particularmente propicio para las proyecciones. Del mismo modo, la oralidad en radio o televisión es un soporte muy importante, en particular en directo, ya que por ejemplo, la voz es un marcador profesional y una funcionalidad, lo que determina un conjunto proyectivo entre los dos que se actualiza especialmente mediante la improvisación de la transmisión en directo. De aquí por ejemplo las alegrías del "directodiferido" en los talk-shows, que conserva la improvisación ahí donde de hecho el documento está grabado. Evidentemente, los dispositivos mediáticos favorecen a través de muchos otros medios, como la frontalidad del presentador que se ofrece a las miradas, o la organización espacial de los micrófonos y cámaras.

Entonces, se pueden estudiar los dispositivos mediáticos a la vez en cuanto proponen inferencias que remiten a la organización de mundos, como en el tratamiento de los textos, imágenes y sonidos mediante la semiología de la imagen, y en cuanto proponen inferencias relativas a la expresión delos oradores que pueblan o describen estos mundos desde un escenario público que han analizado poco gracias al ethos. La presentación radiofónica o televisiva aparece así claramente como una forma escenográfica construida entorno al orador con el fin de que su ethos se mezcle con las representaciones propuestas por los medios, para orientar la lectura de escenas filmadas (Soulez, 1998). Ya sea que se trate de un noticiario, de una emisión de debate o de una revista, la forma en que la voz superpuesta acompaña al auditorio durante la difusión de un reportaje antes de encarnarse en carne y hueso en el seno de este reportaje o en un escenario, ilustra un enredo de inferencias que hay que tratar de desenredar. Pero esta aclaración del ethos constituye a veces la transmisión en sí misma. Así, en el post-face de los reportajes en Envoyé Spécial aparece el orador del cual hasta ahora sólo teníamos la voz superpuesta. Ahora bien, no se trata simplemente de "poner un rostro" a una voz ya que este post-face está lleno de desafíos profesionales (a través de las selecciones realizadas por el periodista, las preguntas son a la vez del ámbito de la deontología y de la "psicología” del orador). Se trata de hacerse una idea 
del orador comparando lo que ha dicho y mostrado (en doble sentido) durante el reportaje con la imagen etótica que ofrece en el programa. Contrariamente a lo que se podría creer, y a las confusiones que podría provocar la metáfora de la "imagen" de sí del orador, el desafío principal no es entonces dar una imagen visual a la voz hasta ahora escuchada, sino más bien utilizar un cuerpo que habla para fijar una serie de imágenes morales.

\section{Referencias bibliográficas}

Amossy, R. (1999). "L'ethos au carrefour des disciplines : rhétorique, pragmatique, sociologie des champs". En: Images de soi dans le discours. Laussane-Paris: Delachaux et Niestlé. pp. 127-154.

Aristoteles (1991). Rhétorique. Trad. Ch.É. Ruelle. Paris: Librairie générale française.

Barthes, R. (1970). “L’ancienne Rhétorique. Aide-mémoire”. Communications Nº16 (Rééd. Seuil Folio. 1994).pp. 254-333.

Ducrot, O. (1984). Le Dire et le Dit. Paris : Minuit.

Eco, U. (1988). Sémiotique et philosophie du langage. Paris: Presses Universitaires de France.

_ (1994). Les limites de l'interprétation. Paris: Biblio Essais.

Gibbard, A. (1996). Sagesse des choix, justesse des sentiments. Théorie du jugement normatif. Paris: Presses Universitaires de France.

Ginzburg, C. (nov. 1980). "Signes, traces, pistes. Racines d'un paradigme de l'indice.' Le Débat N6. pp. 3-44.

Goffman, E. (1981). Façons de parler. Paris: Minuit (ed. 1987).

Jost, F. (1992). Un monde à notre image. Énonciation, cinéma, télévision. Paris: Méridiens Klincksieck.

Maingueneau, D. (1996). «Ethos et argumentation philosophique. Le cas du Discours de la méthode». En: Descartes et l'argumentation philosophique. Paris. pp. 85-110.

Odin, R. (1983). "Pour une sémio-pragmatique du cinéma”. Iris $\mathrm{N}^{\circ} 1$. pp. 67-82.

Perelman, Ch. y Olbrechts-Tyteca, L. (1958). Traité de l'argumentation. Éditions de l'Université de Bruxelles. (ed. 1988).

Sapir, E. (1967). Anthropologie. Paris: Minuit.

Soulez, G. (jun. 1996). Pour une rhétorique de la télévision. Dipl. d'Études Approfondies. Dir. : R. Odin. Université de Paris III.

__ (dic. 1998). La médiation rhétorique à la télévision. Propositions pour une analyse du présentateur comme orateur médiatique. Thèse de doctorat. Dir. : N. Nel. Université de Metz.

_- (2001). “La Rhétorique comme lien entre les théories. L'exemple de la 'crédibilité des journalistes à la radio et à la télévision”. Actes du XIIe Congrès de la SFSIC: Émergence et continuité des recherches en information et communication. pp. 173-180.

_ (2002). "Que signifie 'faire crédit' à un journaliste? Légitimité et crédibilité des journalistes». En: Redéfnitions des territoires de la communication. Bucarest: Éditions Tritonic. pp. 141-156.

_ (2003). "Rhétorique: la sémiologie et son double. De Barthes à la pragmatique". En: Actes du colloque Sémio 2003. Université Paris V.

Veron, E. (1983). "Il est là, je le vois, il me parle”. En: Sociologie de la communication. (Ed. Reader Réseaux, 1997). Paris: CNET. pp. 521-539. 